\title{
Conscientiousness as a Predictor of Relative Longevity
}

\author{
Felix Uchechukwu Udoh $^{1} \&$ Aloysius C. Anyichie ${ }^{2}$ \\ ${ }^{1}$ St. John's University, NY, USA \\ ${ }^{2}$ Department of Educational Counselling Psychology, and Special Education, The University of British \\ Columbia, Vancouver, Canada \\ Correspondence: Felix Uchechukwu Udoh, St. John’s University, NY, USA. E-mail: drucheudoh@yahoo.com
}

Received: October 23, 2015

Accepted: November 4, $2015 \quad$ Online Published: December 17, 2015

doi:10.5539/ijps.v8n1p33

URL: http://dx.doi.org/10.5539/ijps.v8n1p33

\begin{abstract}
This study examined the Conscientiousness domain (of the Big-Five Inventory [B5]) and its facets as predictors of Relative Longevity (RL). Its methods of investigation involved the administration of the B5 to a sample of 350 people from Anambra State (of Nigeria, West Africa) who had RL. These participants were drawn from the representative towns of the three senatorial zones in the State. Stratified sampling technique was employed in the selection of the respondents. Pearson Product-Moment Correlation analysis and Multiple Regression analysis were used in data analyses. The results of the research indicated that there was no significant correlation between Conscientiousness domain and RL. However, its (Conscientiousness) facet (of Thorough) correlated significantly with RL. Besides, Conscientiousness did not predict RL, but its facets (Thorough, Reliable, Organized, and Goal-directed) were found to be significant predictors of RL. The study's conclusion is that although Conscientiousness was neither a correlate nor a predictor of RL among the people of Anambra State, some of its Facets were (correlate and/or predictor/s).
\end{abstract}

Keywords: personality, relative longevity, traits

\section{Introduction}

The age of any population is an important factor in human aspirations and development. Longevity (a measure of how long people live in a particular country or region) can be considered as a predictor of the quality of life of the people as well as an index of national development. Thus, longevity is a phenomenon of interest to individuals, groups, professions and professionals. Some factors are associated with it such as personality (Kern \& Friedman, 2011; Stefanadis, 2010; Ugokwe-Ossai, Udoh, \& Ucheagwu, 2009; Aldwin, Spiro, Lewnson, \& Cupertino, 2001). Personality has been described as a relatively stable set of cognitive and socio-emotional traits and behavioral patterns (Martin, Friedman, \& Schwartz, 2008). Efforts have been made toward the identification of personality traits that predict it among different populations (Friedman \& Kern, 2014; Chapman, Roberts, \& Duberstein, 2011; Hill, Turiano, \& Roberts, 2011; McCrae \& Costa, 1987; Tupes \& Christal, 1961; Fisk, 1949; Cattel, 1943; Allport \& Odbert, 1936). The Five Factor Model (FFM) provides a useful framework for such studies. The FFM posits that human personality can be captured by five broad domains, called the Big Five (B5)-Neuroticism (N), Extraversion (E), Openness to Experience (O), Agreeableness (A), and Conscientiousness (C). O is the newest dimension of the B5 (Piedmont \& Aycock, 2007).

Conscientiousness stands for the propensity to follow socially prescribed norms and rules regarding impulse control and to be able to delay gratification, be goal directed and planful (John \& Srivastava, 1999). It is the tendency towards persistence, industriousness and organization (Marshell, Wortman, Vickers, Kusulas, \& Hervig, 1994). It is characterized positively by traits such as organization, thoroughness, reliability and practicality. Negatively, it is marked by the relative absence of carelessness, negligence and unreliability. People who score high in the personality domain of Conscientiousness are more attentive to health protective practices and health promoting activities (Bogg \& Roberts, 2013; Terracciano et al., 2008), and these variables have large impact on mortality risk (Friedman, Kern, Hampson, \& Duckworth, 2014; Hampson, Edmonds, Goldberg, Dubanoski, \& Hillier, 2013; Hagger-Johnson, Sabia, Nabi, Brunner, Kivimaki, Shipley, \& Singh-Manoux, 2012; Khaw, Wareham, Bingham, Welch, Luben, \& Day, 2008). The major facets of Conscientiousness are impulse control, reliability, conventionality, industriousness and orderliness. 
At the moment, there is paucity of empirical data on the factors that predict longevity in Nigeria. The situation adversely effects the development of social, and health policies. This study investigated the relationship between longevity and the personality domain of Conscientiousness, and whether Conscientiousness (C) and its facets predicted longevity among the population.

\section{Methods}

\subsection{Participants}

The participants were three hundred and fifty $(350: \mathrm{M}=188 ; \mathrm{F}=162)$ adults male and females between the ages of 51 and 99 years (This age bracket is within the individuals who enjoy longevity according to the Nigerian index). They were drawn from three Senatorial Districts of Anambra State, namely Anambra North, Anambra Central and Anambra South, using stratified random sampling technique. The taxonomy of the subjects consisted of the Nigerian old (51-59), and the APA characterization of old age, namely Young old (60-75), Old old (76-85), and Oldest old ( 86 and above) (APA, 2007). A brief description of the participants is as follows: Nigerian old $=$ 159 , Young old $=107$, Old old $=64$ and Oldest old $=20$.

\subsection{Instrument}

The instrument used for this study was the Big Five Inventory (John, Donahue, \& Kentle, 1991). The Big Five Inventory (BFI) is a 44-item inventory developed to assess the five dimensions of personality. The items were structured to reflect the five domains of personality traits, grouped into five major domains: Openness to Experience, Conscientiousness, Extraversion, Agreeableness, and Neuroticism. Each domain is sub-grouped into facets, and the facets contain different number of items; this investigation is concerned with the domain of Conscientiousness.

BFI is structured on 5-point Likert scale (1-Disagree strongly, 2-Disagree a little, 3-Neither agree nor disagree, 4-Agree a little, and 5-Strongly agree). Based on the acclaimed reliabilities and validities of the inventory as used in America and Europe (Rammstedt \& John, 2007; Hampson \& Goldberg, 2006), a pilot study was conducted to determine local reliability and validity of the measure. The sub-scale of Portrait Value Survey (Schwartz, 1992) was used to establish the convergent validity of the instrument. The measures were administered to one hundred and five (105) undergraduate students from the State (Anambra, Nigeria). The validity was $.376, p=<0.01$. The reliability of the instrument was established using test-retest with an interval of two weeks. One hundred and ten pilot participants were used. Cronbach alpha test was used to ascertain the internal consistency of the test during the test and retest periods. The test retest correlation was $.556, \mathrm{p}<0.01$.

\subsection{Procedures}

The instrument was administered on the participants in their homes using research assistants. The participants who could not read and/or write were assisted by the researcher who read the items in the preferred language of the participant and then filled the responses accordingly. In circumstances where the participant preferred that his/her proxies should fill the inventory on his/her behalf, the decision was respected. The researcher, however, stayed nearby to assist as the need arose for the proper filling of the instrument, like ensuring that all the items were responded to. Confidentiality was guaranteed.

There was no time limit for the filling of the inventory in the sense that it was done at the pace dictated by these aged, provided the objective of the data collection was achieved. Special care was taken when dealing with those who were above eighty-six (86) years; this is because some of them were generally not so strong, and have a lot of things to attend to, like the medical regimens. The instruments were collected by the researcher immediately the respondents finished filling them.

\subsection{Analyses}

The raw scores obtained from the field works were subjected to statistical analyses using the software Statistical Procedures for Social Sciences-15 (SPSS-15). The data analyses involved the descriptive statistics of data obtained, the Multiple Regression, the correlations and partial correlations of the data obtained as well as the ANCOVA. Multiple Regression analysis was used to determine the predictive strengths, as well as the contributions of the factor and its facets in the overall involvement in longevity. The partial correlation was employed to control for sex, education and income. It was adjudged that such variables may confound the data obtained. Subsequently, a 2-Way Analysis of Covariance was employed. Education and income as covariates in the analysis of variance were used as part of the efforts to control for extraneous variables that may influence the results of the main variables (gender and age). 


\section{Results}

Table 1. Means and standard deviation of RL and C (of B5) with its facets among the people of Anambra state $(\mathrm{N}=350)$

\begin{tabular}{lcc}
\hline & Mean & Standard Deviation \\
\hline Relative Longevity & 64.9521 & 11.8514 \\
Conscientiousness & 3.9845 & .8379 \\
Thorough facet & 3.7863 & 1.0302 \\
Reliable facet & 3.9438 & 1.0002 \\
Organized facet & 3.9928 & 1.0139 \\
Goal-directed facet & 4.2206 & 2.6910 \\
Task-oriented facet & 4.0299 & 1.1698 \\
\hline
\end{tabular}

Table 2. Correlation between RL and conscientiousness factor among the people of Anambra state $(\mathrm{N}=350)$

\begin{tabular}{cc}
\hline Participants & $\mathrm{R}$ \\
\hline RL x Conscientiousness & .034 \\
\hline
\end{tabular}

*Correlation is significant at the 0.05 level (1-tailed)

$\mathrm{RL}=$ Relative Longevity

B5 = Big-Five

The table showed that Conscientiousness has no significant relationship with RL among the people of Anambra State.

Table 3. Correlation between RL and the facets of conscientiousness among the people of Anambra state $(\mathrm{N}=$ 350)

\begin{tabular}{ll}
\hline Participants & $\mathrm{R}$ \\
\hline RL x Thorough facet & $.114^{*}$ \\
RL x Reliable facet & .071 \\
RL x Organized facet & -.067 \\
RL x Goal-directed facet & -.061 \\
RL x Task-oriented facet & -.002
\end{tabular}

*Correlation is significant at the 0.05 level (1-tailed)

$\mathrm{RL}=$ Relative Longevity

B5 = Big-Five

The table highlighted the nature of the correlation between RL and the Facets of Conscientiousness of the B5 among the people of Anambra State. It showed that RL correlated significantly with the Thorough Facet of the Domain of Conscientiousness. 
Table 4. Predictive strength of conscientiousness for RL among the people of Anambra state (Multiple Regression Analysis) $(\mathrm{N}=35)$

\begin{tabular}{lllllll}
\hline \multicolumn{7}{c}{ Coefficients } \\
\hline Model & $\begin{array}{l}\text { Unstandardized } \\
\text { Beta }\end{array}$ & $\begin{array}{l}\text { Standardized } \\
\text { Beta }\end{array}$ & R2 & Calculated & & (Sig) \\
& Constant & 65.205 & & & 9.463 & P \\
Conscientiousness & .870 & .0488 & .017 & .668 & 1.04 & Ns \\
\hline
\end{tabular}

Dependent Variable: Relative Longevity

The R2 $=.017$, showed that Conscientiousness had impact on RL, but the predictive strength was not significant.

Table 5. Predictive strength of the facets of conscientiousness for RL among the people of Anambra state $(\mathrm{N}=$ 350) (Multiple Regression Analysis)

\begin{tabular}{lcc|c|c|c|c}
\hline Model & Unstandardized & Standardized & R2 & $\begin{array}{c}\text { Calculated } \\
\mathrm{T}\end{array}$ & $\mathrm{F}$ & $\begin{array}{c}\text { (Sig) } \\
\end{array}$ \\
& Beta & Beta & & & \\
\hline (Constant) & 69.920 & & & 6.545 & & .051 \\
Thorough facet & 1.694 & .139 & & 1.960 & & \\
Reliable facet & 2.526 & .202 & & 2.759 & 2.574 & .006 \\
Organized facet & -1.727 & -.132 & \multirow{2}{*}{0.265} & -1.786 & & .076 \\
Goal-directed facet & -2.651 & -.192 & & 2.562 & & .011 \\
Task-oriented facet & -.194 & -.018 & & -.249 & & Ns \\
\hline
\end{tabular}

Dependent Variable: Relative Longevity

The R2 $=0.265$, indicated that the Facets of Thorough, Reliable, Organized, and Goal-directed had significant predictive strength for the Relative Longevity of the people of Anambra State. The predictive strengths of these Facets were significantly different $(\mathrm{F}=2.574, \mathrm{p}<.001)$.

\section{Discussion}

Consistent with previous investigations (Weiss \& Costa, 2005; Wilson, de Leon, Bienias, Evans, \& Bennett, 2004; Christensen et al., 2002), this study showed that Conscientiousness did not significantly correlate with RL. However, further investigation revealed that its facet (Thorough) has a significant correlation with RL (.114). The reason for the correlation not being significant might be because there was no striking difference in the scores of the participants on Conscientiousness and RL. Terracciano and colleagues (2008) found that when the scores on measure of Conscientiousness were trichotomized, the results revealed that those whose scores were high had about a $26 \%$ lower risk of dying during the course of the study as compared with the least active individuals. Interestingly, further analysis indicated that there was no significant difference in risk between participants with average, as compared to low scorers. Consistent with these (Terraciano and others') findings, it might mean that the participants' scores on correlation found between the scores of the participants on Conscientiousness were not outstanding. The fact that it was only the Thorough facet that significantly correlated with RL collaborate the above explanation. This, however, calls for more investigation. The plausible explanation for the significance of the score of the people of Anambra State in Thorough facet is that the people are more disposed to doing things more properly as they advance in years. They are more eager to do things the best way that they can. It is a truism that experience is the best teacher: the experiences of these people inform the prudence in being thorough in their dealings. The population of the participants has a proverb which 
maintains: "a stick does not pitch one's eye twice" (Ofu osisi a dighi adu madu na anya ugboro na-abo). This implies that one is expected to learn from his mistakes, and as such avoid subsequent ones (mistakes).

Further, the findings of the study indicated that the facets of Thorough, Reliable, Organized, and Goal-directed were significant predictors of RL. Being thorough can guarantee the removal of the foreseeable life-threats. Among the people (of Anambra State), life-threatening crimes (such as kidnapping and armed robbery) abound. The situation exposes the people to myriad of emotional stress. And these stresses militate against the people's life and longevity (Danner, Snowdon, \& Friesen, 2001; Lazarus, 1991). Most people who are thorough do not fall victim to these dangers; therefore, they are more likely to live longer. Similarly, Thorough (thoroughness) can encourage the individual toward embarking on novel beneficial acts. The facet of reliable has many positive consequences for the individual who has it and for others with whom she interacts. It (Reliable) enhances one's experiences of calmness, and reduced tension and stress (Masui, Gondo, Inagaki, \& Hirose, 2006). These reinforce better interactions with others, and have reciprocating effects on the individual. As the people struggle with the prevailing crimes and the vicissitudes, those who feel and are adjudged reliable are more predisposed for better life, including longevity (Costa, Somerfield, \& McCrea, 1996). Besides, one of the major causes of death among the people of Anambra State is accidents. These people from Anambra State who enjoy relative longevity, therefore, are likely to have lifestyles that safeguard them from undue stresses which are usually associated with unplanned/unorganized lifestyles. Such lifestyles involve things like regular and adequate amount of sleep, engaging in regular physical activities and the maintenance of healthy body weight. Again, the people of Anambra State who are goal-directed are known to be disposed to embark on something (e.g., the formation of a behavioral pattern). They are also ready to give up/let go of things (health-hazard habits like smoking) for the attainment of goals. They adapt to challenges, including those of development. Thus, the attainment of relative longevity by these people is not a surprise (Walworth, Rumana, Nguyen, \& Jarred, 2008; Friedman, Tucker, Tomlinson-Keasey, Schwart, Wingard, \& Criqui, 1993).

Among the limitations of this research is the sample size of the participants. An all-towns based survey of larger participants would have provided a more robust representative profile of relative longevity in the cohort. The scope of the analysis was limited to gender, education, income, and lifestyles. The inclusion of more factors (guaranteed by financial and other logistic provisions) is a better bet for the realization of deeper insights.

Recommendations for future directions are apt. A measure of conscientiousness trichotomizing its scores will provide further insight into why it was only a facet of conscientiousness (and not the whole factor or all its facets) that correlate with longevity. Sequel to the findings of this investigation, these predictive facets of conscientiousness should be worked on, with the goal of facilitating their inculcation, enhancement and protection among the populace in particular and the world in general. More funding and studies on the personality predictors of longevity should be encouraged in Nigeria and other countries that share her demographic variables.

\section{Conclusion}

This study lends support to the supposition that the facets of Conscientious are important to human longevity. The development/enhancement of the pro-longevity facets should be encouraged among the population of the study and others who share similar groups. Such efforts will promote their lives, and ensure their better contribution to humanity (Enyekit, Ubulom, \& Onuekwa, 2011).

\section{References}

Aldwin, C. M., Spiro, A., Levenson, M. E., \& Cupertino, A. P. (2001). Longitudinal findings from the normative aging study: Personality, health trajectories, and mortality. Psychology and Aging, 16, 450-465. http://dx.doi.org/10.1037/0882-7974.16.3.450

Allport, G. W., \& Odbert, H. S. (1936). Trait-names: A psycho-lexical study. Psychological Monographs, 47(211). http://dx.doi.org/10.1037/h0093360

Bogg, T., \& Roberts, B. W. (2013). The case for conscientiousness: Evidence and implications for a personality trait marker of health and longevity. Annals of Behavioral Medicine, 45(3), 278-288. http://dx.doi.org/10.1007/s12160-012-9454-6

Chapman, B. P., Roberts, B., \& Duberstein, P. (2010). Personality and longevity: Knowns, unknowns, and implications for public health and personalized medicine. Journal of Aging Research, 2011.

Cattle, R. B. (1943). The description of personality: Basic traits resolved into clusters. Journal of Abnormal and Social Psychology, 38, 476-506. http://dx.doi.org/10.1037/h0054116 
Christensen, A. J., Ehlers, S. L., Wiebe, J. S., Moran, P. J., Raichle, K., Kerneyhough, K., \& Lawton, W. J. (2002). Patient personality and mortality: A 4-year perspective examination of chronic renal efficiency. Health Psychology, 21, 315-320. http://dx.doi.org/10.1037/0278-6133.21.4.315

Costa, P. T. Jr., Somerfield, M. R., \& McCrea, R. R. (1996). Personality and coping: A re-conceptualization. In A. Terrecciano, C. E. Lockenlioff, A. B. Zonderman, L. Ferrucci, \& P. T. Jr. Costa (Eds.), Personality predictors of longevity: Activity, Emotional Stability and Conscientiousness.

Danner, D. D., Snowdon, D. A., \& Friesen, W. (2001). Positive emotions in early life and longevity: Findings from nun study. Journal of Personality and Social Psychology, 80, 804-813. http://dx.doi.org/10.1037/0022-3514.80.5.804

Enyekit, E. O., Ubulom, W. J., \& Onuekwa, F. A. (2011). Achieving human capital development in Nigeria through vocational education for nation building. Academic Research International, SAVAP International.

Fiske, D. W. (1949). Consistency of the factional structures of personality ratings from different sources. Journal of Abnormal and Social Psychology, 44, 329-344. http://dx.doi.org/10.1037/h0057198

Friedman, H. S., \& Kern, M. L. (2014). Personality, well-being, and health. Annual Review of Personality, 65, 719-742. http://dx.doi.org/10.1146/annurev-psych-010213-115123

Friedman, H. S., Kern, M. L., Hampson, S. E., \& Duckworth, A. L. (2014). A new life-span approach to conscientiousness and health: Combining the pieces of the causal puzzle. Developmental Psychology, 50(5), 1377-1389. http://dx.doi.org/10.1037/a0030373

Friedman, H. S., Tucker, J. S., Tomlinson-Keasey, C., Schwartz, J. E., Wingard, D. L., \& Criqui, M. H. (1993). Does childhood personality predict longevity? Journal of Personal and Social Psychology, 65, 176-185. http://dx.doi.org/10.1037/0022-3514.65.1.176

Hagger-Johnson, G., Sabia, S., Brunner, E., Kivimaki, M., Shipley, M., \& Singh-Manoux, A. (2012). Low conscientiousness and risk of all-cause, cardiovascular and cancer mortality over 17 years: Whitehall II cohort study. Journal of Psychosomatic Research, 73(2), 98-103. http://dx.doi.org/10.1016/j.jpsychores.2012.05.007

Hampson, S. E., Edmonds, G. W., Goldberg, L. R., Dubanoski, J. P., \& Hillier, T. A. (2013). Childhood conscientiousness relates to objectively measured adult physical health four decades later. Health Psychology, 32(8), 925-928. http://dx.doi.org/10.1037/a0031655

Hampson, S. E., \& Goldberg, L. R. (2006). A first large cohort study of personality traits stability over 40 years between elementary school and midlife. Journal of Personality and Social Psychology, 91, 763-779. http://dx.doi.org/10.1037/0022-3514.91.4.763

Hill, P. L., Turiano, N. A., \& Roberts, B. W. (2011). Conscientiousness and longevity: An examination of possible mediators. Health Psychology, 30(5), 536-541. http://dx.doi.org/10.1037/a0023859

John, O. P., Donahue, E. M., \& Kentle, R. L. (1991). The Big Five Inventory-versions 49 and 54. Berkeley: University of California, Berkeley Institute of Personality and Social Research.

John, O. P., \& Srivastava, S. (1999). The Big-Five trait taxonomy: History, measurement and theoretical perspectives. In L. Pervin, \& O. P. John (Eds.), Handbook of Personality: Theory and Research (8th ed.). New York: Guilford.

Khaw, K. T., Wareham, N., Bingham, S., Welch, A., Luben, R., \& Day, N. (2008). Combined impact of health behaviours and mortality in men and women: The EPIC-Norfolk Population study. Journal of Psychological Medicine, 5, 1-12.

Lazarus, R. S. (1991). Emotion and Adaptation. New York: Oxford University Press.

Marshall, G. N., Wortman, C. B., Vickers, R. R. Jr., Kusular, J. W., \& Hervig, L. K. (1994). The Five-Factor Model of Personality as a Framework for Personality-Health Research. Journal of Personality: APA.

Martin, L. R., Friedman, H. S., \& Schwartz, J. E. (2008). Personality and mortality across the life span: The importance of conscientiousness as a biopsychological attribute. Health Psychology, 26, 428-436. http://dx.doi.org/10.1037/0278-6133.26.4.428

Masui, J., Gondo, Y., Inagaki, H., \& Hirose, N. (2006). Do personality characteristics predict longevity? $\begin{array}{llllll}\text { Findings from } & \text { Tokyo } & \text { Centenarian } & \text { Study. }\end{array}$ http://dx.doi.org/10.1007/s11357-006-9024-6 
McCrae, R. R., \& Costa, P. T. (1987). Validation of the Five-Factor model of personality across instruments and observers. Journal of Personality and Social Psychology, 52, 81-90. http://dx.doi.org/10.1037/0022-3514.52.1.81

Piedmont, R. L., \& Aycock, W. (2007). An historical analysis of the lexical emergence of the Big-Five personality adjective descriptors. Personality and Individual Differences, 42(6), 1059-1068. http://dx.doi.org/10.1016/j.paid.2006.09.015

Rammstedt, B., \& John, O. P. (2007). Measuring personality in one minute or less: A 10-item short version of the Big Five Inventory in English and German. Journal of Research in Personality, 41, 203-212. http://dx.doi.org/10.1016/j.jrp.2006.02.001

Schwartz, S. H. (1992). Universals in the content and structure of values: Theoretical and empirical test in 20 countries. In M. Zanna (Ed.), Advances in Experimental Social Psychology. San Diego: Academic Press.

Stefanadis, C. I. (2010). Seeking the secrets of longevity. Hellenic Journal of Cardiology, 51, 479-480.

Terracciano, A., Lockenlioff, C. E., Zonderman, A. B., Ferrucci, L., \& Costa, P. T. Jr. (2008). Personality predictors of longevity: Activity, Emotional Stability and Conscientiousness. http://dx.doi.org/10.1097/psy.0b013e31817b9371

Tupes, E. C., \& Christal, R. C. (1961). Recurrent personality factors based on trait ratings. Technical Report, USAF, Lackland Air force Base, TX. http://dx.doi.org/10.1037/e531292008-001

Ugokwe-Ossai, R. N., Udoh, F. U., \& Ucheagwu, V. A. (2009). Personality and family environment as predictors and correlates of recovery from depression. Journal of Behavioural Sciences, 2(2).

VandeBos, G. R. (Ed.). (2007). APA Dictionary of Psychology. Washington, DC: American Psychological Association, AUTHOR.

Walworth, D., Rumana, C. S., Nguyen, J., \& Jarred, J. (2008, FALL). Effect of live music therapy sessions on quality of life indicators, meditation. Journal of Music Therapy, 45(3), 345-349. http://dx.doi.org/10.1093/jmt/45.3.349

Weiss, A., \& Costa, P. T. Jr. (2005). Domain and facet of personality predictors of all-cause mortality among

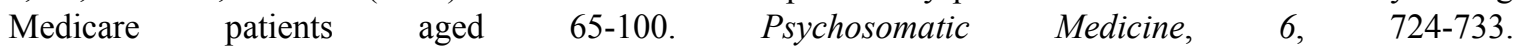
http://dx.doi.org/10.1097/01.psy.0000181272.58103.18

Wilson, R. S., de Leon, C. F, M., Biennias, J. L., Evans, D. A., \& Bennett, D. (2004). Personality and mortality in old age. Journal of Gerontology: Psychological Science, 59B, 110-116. http://dx.doi.org/10.1093/geronb/59.3.P110

Takahashi, Y., Edmonds, G. W., Jackson, J. J., \& Roberts, B. W. (2013). Longitudinal correlated changes in conscientiousness, preventative health-related behaviors, and self-perceived physical health. Journal of Personality, 81(4), 417-427. http://dx.doi.org/10.1111/jopy.12007

\section{Copyrights}

Copyright for this article is retained by the author(s), with first publication rights granted to the journal.

This is an open-access article distributed under the terms and conditions of the Creative Commons Attribution license (http://creativecommons.org/licenses/by/3.0/). 